\title{
Synthesis and Application of Polystyrene Having Triethylene Glycol Moieties for Liquid-Phase Organic Synthesis (LPOS)
}

\author{
Osamu Shimomura ${ }^{a}$, Takeki Hosokawa ${ }^{a}$, and Ryôki Nomura ${ }^{a, b}$ \\ ${ }^{a}$ Department of Applied Chemistry, and ${ }^{b}$ NMRC, Osaka Institute of Technology, \\ 5-16-1 Ô-miya, Asahi-ku, Osaka, 535-8585, \\ FAX: +81-6-6954-4269, e-mail: shimomura@chem.oit.ac.jp
}

To use as a soluble scavenger resin, polystyrene having triethylene glycol moieties was prepared from copolymerization of 2-\{2-[2-(4-vinylphenoxy)ethoxy]ethoxy\}ethanol (2) with styrene (St). The terminal hydroxyl group of the obtained copolymer (3) was reacted with 4-hydroxybenzaldehyde to obtain the polystyrene (4) having formyl group. To functionalize 3 further, the terminal hydroxyl group was reacted with diketene to obtain the polystyrene (6) having $\beta$-ketoester. Reactions of $\mathbf{4}$ and $\mathbf{6}$ with benzylamine were investigated to confirm their abilities for scavenger resin. The performances of those soluble polymers for scavengers were thoroughly investigated.

Key words: combinatorial organic chemistry, LPOS, polymer scavenger, triethylene glycol, $\beta$-ketoester

\section{INTRODUCTION}

A technique of combinatorial chemistry has been widely used for not only drug discovery but also materials chemistry [1-3]. Preparation of a library of organic small molecules in the field of combinatorial organic chemistry, the purity of the resultants is of importance for the evaluation of the performance of each compound. To improve the purity, scavenger resins have been widely used for liquid phase organic syntheses (LPOS) [4-8]. Various types of resins for scavenger have been already reported and some resins are commercially available [9]. Whereas these commercial resins are prepared from cross-linked polystyrene, which might be brought some disadvantages in hydrophilic solvent such as methanol. Moreover, those resins are insoluble in solvent, the excess equivalents of scavenger resins will be used for objective compounds. Therefore we prepared non-cross-linked polystyrene having triethylene glycol moieties as a hydrophilic structure. The terminal hydroxyl group of the polymer was converted to arylaldehyde and $\beta$-ketoester as scavenger of primary amines.

\section{EXPERIMENTAL}

2.1 Measurements.

${ }^{1} \mathrm{H}$ and ${ }^{13} \mathrm{C}$ NMR spectra were recorded in $\mathrm{CDCl}_{3}$ on a Varian Unity-300 spectrometer using tetramethylsilane (TMS) as an internal standard. Gel permeation chromatographic analyses (GPC) were carried out on a Shimadzu LC-10ADvp, DGU-12A, CTO-10Avp, C-R7Aplus, RID-10A RI detector and a Shimadzu SPD-10ADvp UV-vis detector (254 nm) (Shim-pack GPC-803, THF as eluent) calibrated with polystyrene standards. Melting points were obtained with a Yanaco mp-J3 apparatus.

$2.2 \quad$ Preparation of

2-\{2-[2-(4-vinylphenoxy)ethoxy]ethoxy\}ethanol (2).
A mixture of 4-acetoxystyrene $(1,1.00 \mathrm{~g}, 6.17 \mathrm{mmol})$ and sodium hydroxide $(61.6 \mathrm{mg}, 15.4 \mathrm{mmol})$ in DMSO $(6 \mathrm{ml})$ was stirred at $60^{\circ} \mathrm{C}$ under $\mathrm{N}_{2}$. After $6 \mathrm{~h}$, triethylene glycol monochlorohydrin $(1.25 \mathrm{~g}, 7.39$ $\mathrm{mmol}$ ) was added dropwise to the solution at rt. After the reaction confirmed by TLC, water $(80 \mathrm{ml})$ was added to the solution and was extracted with diethyl ether. The organic layer was washed with water and brine, and dried over $\mathrm{MgSO}_{4}$, and filtered off. After evaporation of the solvent, the residue was separated by column chromatography on silica gel (solvent: ethyl acetate : hexane $=3: 1)$. Yield: $58 \%$.

${ }^{1} \mathrm{H}-\mathrm{NMR}\left(\mathrm{CDCl}_{3}, 300 \mathrm{MHz}\right) \delta$ 7.37-7.27, 6.89-6.84 (m, aromatic), $6.64\left(\mathrm{dd}, \mathrm{CH}_{2}=\mathrm{C} \underline{H}-\right), 5.60\left(\mathrm{~d},-\mathrm{CH}=\mathrm{C}_{2} \mathrm{cis}\right)$, 5.11 (d, $-\mathrm{CH}=\mathrm{C} \underline{H}_{2}$ trans $), 4.11\left(\mathrm{~m}, \mathrm{Ar}-\mathrm{C}_{H_{2}}-\mathrm{CH}_{2}-\right), 3.84$ (m, $\quad \mathrm{Ar}-\mathrm{CH}_{2}-\mathrm{C}_{2^{-}}$), 3.73-3.65 (m, -O-C $\left.\underline{H}_{2} \mathrm{CH}_{2}-\mathrm{O}-\mathrm{C} \underline{H}_{2}-\mathrm{C} \underline{H}_{2}-\mathrm{OH}\right), \quad 3.69 \quad(\mathrm{~m}$, $-\mathrm{CH}_{2}-\underline{\mathrm{H}}_{2}-\mathrm{O}-\mathrm{CH}_{2}-\mathrm{CH}_{2}-\mathrm{OH}$ ), 1.86 (br, $\left.-\mathrm{O} \underline{\mathrm{H}}\right)$. Mp: 33.5 $-34.0^{\circ} \mathrm{C}$.

\subsection{Copolymerization of 2 with styrene $(\mathrm{St})$.}

A mixture of $2(0.476 \mathrm{~g}, 1.89 \mathrm{mmol})$, St $(1.00 \mathrm{~g}, 9.60$ $\mathrm{mmol}$ ), AIBN (0.027 g, $3 \mathrm{~mol} \%$ for monomer), and THF (3 ml) was placed in an ampoule, which was cooled, degassed, and sealed in vacuo. After stirring at $60^{\circ} \mathrm{C}$ for $20 \mathrm{~h}$, the reaction mixture was dissolved in chloroform $(15 \mathrm{ml})$, and the solution was poured into excess amount of ethanol $(1000 \mathrm{ml})$. The resulting precipitate (3) was separated by filtration and dried in vacuo. Yield: $55 \%$.

${ }^{\mathrm{l}} \mathrm{H}-\mathrm{NMR}\left(\mathrm{CDCl}_{3}, 300 \mathrm{MHz}\right) \delta$ 7.2-6.2 (br, aromatic), 4.04 (br, Ar-O-C $\underline{H}_{2}-\mathrm{CH}_{2}$ ), 3.84 (br, Ar-O- $\mathrm{CH}_{2}-\mathrm{CH}_{2}$ ), 3.72 (br, $-\mathrm{O}-\mathrm{C}_{2} \mathrm{CH}_{2}-\mathrm{O}-\mathrm{C}_{2}-\underline{\mathrm{C}}_{2}-\mathrm{OH}$ ), 3.62 (br, $\left.-\mathrm{CH}_{2}-\mathrm{CH}_{2}-\mathrm{O}-\mathrm{CH}_{2}-\mathrm{CH}_{2}-\mathrm{OH}\right), 2.15$ (br, $\left.-\mathrm{OH}\right), 2.1-1.0$ (br, main chain).

2.4 Reaction of 4-hydroxybenzaldehyde with 3 .

A mixture of $3(0.106 \mathrm{~g})$, 4-hydroxybenzaldehyde (32.0 $\mathrm{mg}, 0.262 \mathrm{mmol})$, triphenylphosphine $(0.0729 \mathrm{~g}$, 
Scheme 1. Preparation of 2-\{2-[2-(4-vinylphenoxy)ethoxy]ethoxy\}ethanol (2).<smiles>C=Cc1ccc(OC(C)=O)cc1</smiles>
1) $\mathrm{NaOH}$, DMSO 1

Scheme 2. Radical copolymerization of 2 with St.<smiles>C=Cc1ccccc1</smiles>

$0.278 \mathrm{mmol})$, and THF $(2 \mathrm{ml})$ was stirred at $-15^{\circ} \mathrm{C}$ under $\mathrm{N}_{2}$. A THF $(1 \mathrm{ml})$ solution of diethyl azodicarboxylate (DEAD, $76.0 \mathrm{mg}, 0.175 \mathrm{mmol}$ ) was added dropwise to the solution. After $16 \mathrm{~h}$ at $\mathrm{rt}$, the reaction mixture was poured to ethanol $(60 \mathrm{ml})$. The resulting white precipitate was separated by filtration and dried in vacuo. Yield: 98\%.

${ }^{1} \mathrm{H}-\mathrm{NMR}\left(\mathrm{CDCl}_{3}, 300 \mathrm{MHz}\right) \delta 9.86(\mathrm{~s}, \mathrm{Ar}-\mathrm{C} \underline{\mathrm{HO}}), 7.81$ (d, $\mathrm{CHO}-\underline{A r}$ ), 7.2-6.2 (br, aromatic), 4.21 (br, CHO-Ar-O-C $\mathrm{H}_{2-}$ ), 4.04 (br, -CH-Ar-O-CH${ }_{3}-\mathrm{CH}_{2-}$ ), 3.89 (br, $\quad \mathrm{CHO}-\mathrm{Ar}-\mathrm{O}-\mathrm{CH}_{2}-\mathrm{C}_{2}$ ), 3.83 (br, -CH-Ar-O-CH${ }_{2}-\underline{C}_{2}-$ ), 3.76 (br, $\quad-\mathrm{O}-\mathrm{C}_{2} \underline{\mathrm{C}}_{2}-\mathrm{O}-$ ), 2.1-1.0 (br, main chain).

\subsection{Scavenging reaction of 4 with benzylamine.}

A mixture of $4(0.040 \mathrm{~g})$, benzylamine $(5.50 \mu 1,50.4$ $\mu \mathrm{mol})$, and THF $(2 \mathrm{ml})$ was stirred at $\mathrm{rt}$ under $\mathrm{N}_{2}$. After $20 \mathrm{~h}$, the solution was poured to ethanol $(50 \mathrm{ml})$. The resulting white precipitate was separated by filtration and dried in vacuo. Yield: $99 \%$.

${ }^{1} \mathrm{H}-\mathrm{NMR}\left(\mathrm{CDCl}_{3}, 300 \mathrm{MHz}\right) \delta 9.86$ (s, Ar-C $\left.\underline{\mathrm{HO}}\right), 8.31$ (br, $\mathrm{Ar}-\mathrm{C} \underline{H}=\mathrm{N}), 7.81$ (d, CHO- $\underline{\mathrm{Ar}}$ ), 7.2-6.2 (br, aromatic), 4.95 (br, =N-C $\left.\underline{H}_{2}-\right), 4.20$ (br, CHO-Ar-O-C $\underline{H}_{2}^{-}$), 4.04 (br, $\mathrm{Ar}-\mathrm{O}-\mathrm{C} \underline{H}_{2}-\mathrm{CH}_{2-}$ ), 3.84 (br, CHO-Ar-O- $\mathrm{CH}_{2}-\mathrm{C}_{2}-$, $\mathrm{Ar}-\mathrm{CH}_{2}-\mathrm{C}_{2}{ }_{2}^{-}$), 3.76 (br, -O-C $\underline{H}_{2} \mathrm{C}_{2}-\mathrm{O}-$ ), 2.1-1.0 (br, main chain).

\subsection{Reaction of diketene with 3 .}

A mixture of $3(0.108 \mathrm{~g})$, DMAP (34.2 $\mathrm{mg}, 0.280$ $\mathrm{mmol})$, and dichloromethane $(2 \mathrm{ml})$ was stirred at $-78^{\circ} \mathrm{C}$ under $\mathrm{N}_{2}$. A dichloromethane $(1 \mathrm{ml})$ solution of diketene $(20.0 \mu \mathrm{l}, 0.262 \mathrm{mmol})$ was added dropwise to the solution. After $16 \mathrm{~h}$ at $\mathrm{rt}$, the reaction mixture was poured to ethanol $(100 \mathrm{ml})$. The resulting pale yellow precipitate was separated by filtration and dried in vacuo. Yield: quant.

${ }^{1} \mathrm{H}-\mathrm{NMR}\left(\mathrm{CDCl}_{3}, 300 \mathrm{MHz}\right) \delta$ 7.2-6.2 (br, aromatic), 4.31 (br, $\mathrm{CH}_{2} \underline{\mathrm{CH}}_{2}$-OCO-), 4.03 (br, $\mathrm{Ar}-\mathrm{C}_{2} \underline{\mathrm{CH}}_{2}-\mathrm{CH}_{2}$ ), 3.83 (br, $\quad \mathrm{Ar}-\mathrm{O}-\mathrm{CH}_{2}-\mathrm{C}_{2^{-}}$), 3.72 (br,

Table 1. Solubility of 3 .

\begin{tabular}{|c|c|c|c|c|c|c|c|c|c|}
\hline hexane & $\mathrm{CHCl}_{3}$ & $\mathrm{Et}_{2} \mathrm{O}$ & THF & 1,4-Dioxane & acetone & $\mathrm{CH}_{3} \mathrm{OH}$ & DMF & $\overline{\text { DMSO }}$ & Water \\
\hline- & + & + & + & + & + & - & + & + & - \\
\hline
\end{tabular}

Scheme 3. Reaction of 4-hydroxybenzaldehyde with $\mathbf{3}$.
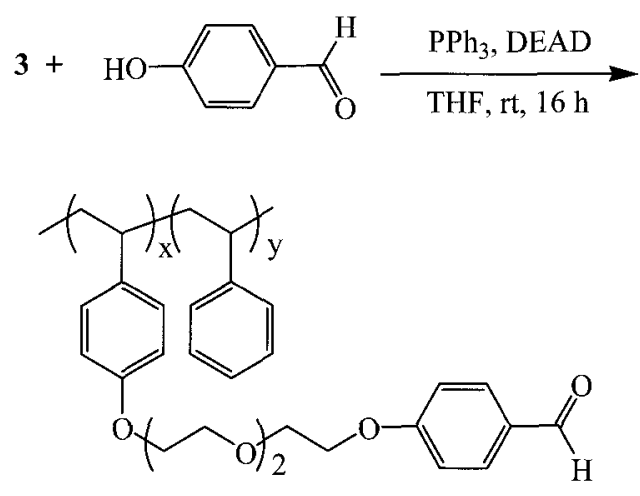

4

Scheme 4. Scavenger model reaction of 4 with benzylamine.
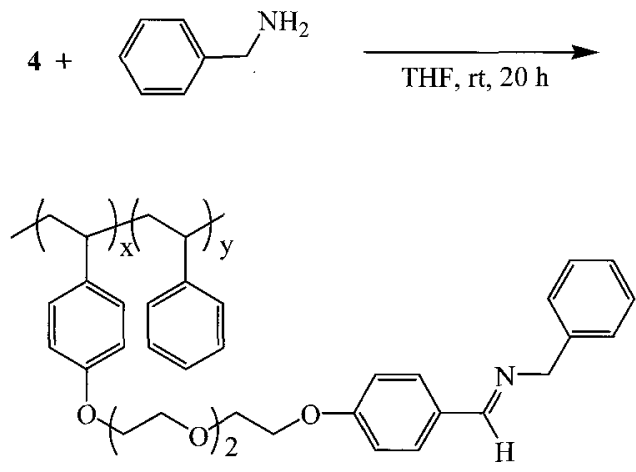

5

-O-C $\left.\underline{H}_{2} \mathrm{C}_{2}-\mathrm{O}-\mathrm{C} \underline{H}_{2}-\mathrm{CH}_{2}-\mathrm{OCO}-\right), \quad 3.47 \quad$ (br, OCO-C $\left.\underline{H}_{2}-\mathrm{CO}-\right), 2.24$ (br,-CO-C $\underline{H}_{3}$ ), 2.1-1.0 (br, main chain).

2.7 Scavenging reaction of 6 with benzylamine.

A mixture of $6(62.5 \mathrm{mg})$, benzylamine $(12.8 \mu 1,11.8$ $\mu \mathrm{mol})$, and THF $(2 \mathrm{ml})$ was stirred at $\mathrm{rt}$ under $\mathrm{N}_{2}$. After $20 \mathrm{~h}$, the solution was poured into ethanol $(50 \mathrm{ml})$. The resulting white precipitate was separated by filtration and dried in vacuo. Yield: $97 \%$.

${ }^{1} \mathrm{H}-\mathrm{NMR}\left(\mathrm{CDCl}_{3}, 300 \mathrm{MHz}\right) \delta$ 7.37-7.29 (m, $\underline{P h}-\mathrm{CH}_{2}$ ), 7.2-6.2 (br, aromatic), 4.51 (br, $\mathrm{C}_{2}$-OCO-, - $\underline{\mathrm{H}}=\mathrm{C}-$ ), 4.24 (br, $\mathrm{Ph}-\mathrm{C}_{2}$ ), 4.02 (br, Ar-O-C $\underline{H}_{2}-\mathrm{CH}_{2}$ ), 3.83 (br, Ar-O- $\left.\mathrm{CH}_{2}-\underline{\mathrm{C}}_{2}{ }^{-}\right) 3.70$ (br, -O-C $\underline{H}_{2}-\mathrm{C} \underline{H}_{2}-\mathrm{O}-\mathrm{C} \underline{H}_{2}-\mathrm{CH}_{2}-\mathrm{OCO}-$ ), 2.1-1.0 (br, main chain).

\section{RESULTS AND DISCUSSION}

\subsection{Copolymerization of 2 with St.}

To simplify the purification from the reaction mixture in solution phase, scavenger resin is used for isolation of the target compound. Therefore a soluble polymer scavenger of polystyrene having triethylene glychol as graft chains was investigated. To make a St monomer having triethylene glychol structure, 4-acetoxystyrene (1) was reacted with sodium hydroxide in DMSO at $60^{\circ} \mathrm{C}$ for $6 \mathrm{~h}$ under $\mathrm{N}_{2}$. After the reaction, triethylene glycol monochlorohydrin was added to the solution to obtain the monomer 2 (Scheme 1). The radical copolymerization of 2 with $\mathrm{St}$ was carried out at $60^{\circ} \mathrm{C}$ 


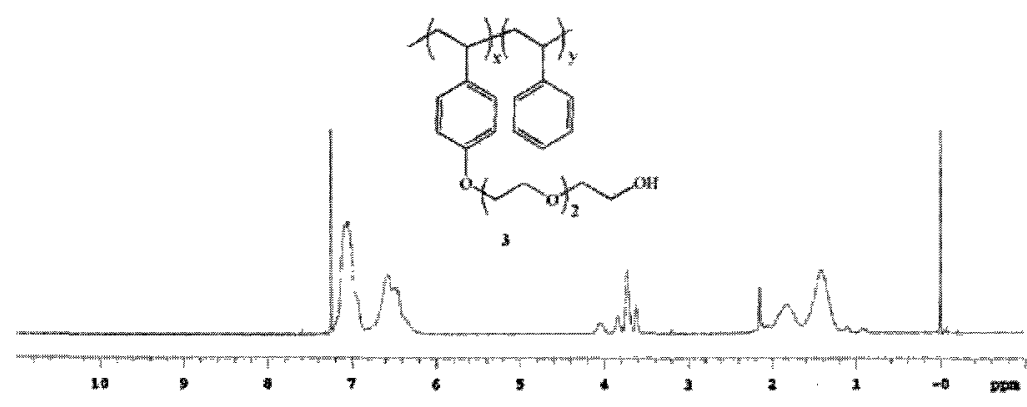

Fig. $1{ }^{1} \mathrm{H}-\mathrm{MMR}$ of 3 ,
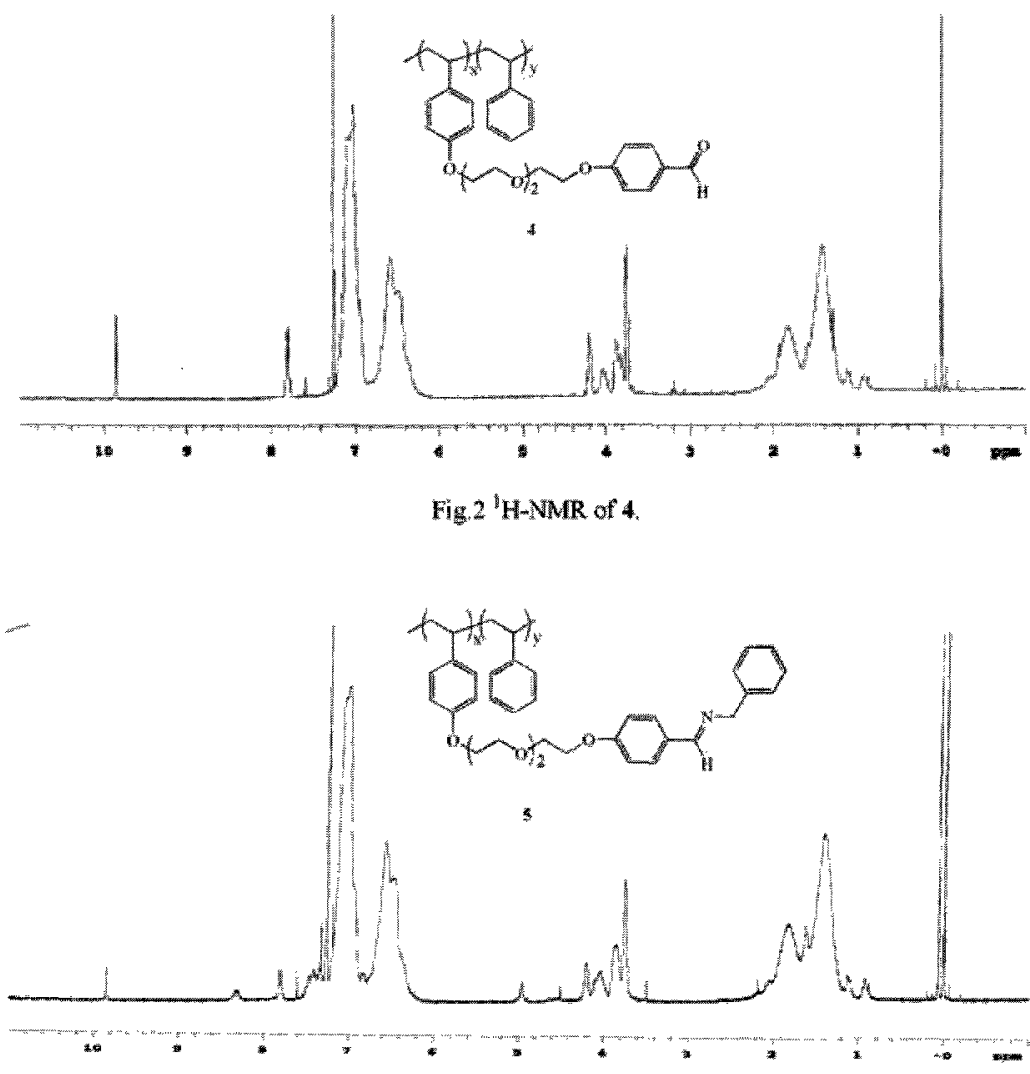

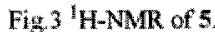

for $20 \mathrm{~h}$ in THF by using $3 \mathrm{~mol} \%$ of AIBN to give a polymer 3 in $55 \%$ yield (Scheme 2). ${ }^{1} \mathrm{H}-\mathrm{NMR}$ spectrum of the obtained polymer is shown in Figure 1. The ${ }^{1} \mathrm{H}-\mathrm{NMR}$ spectrum shows the complete disappearance of the double bond $\left(-\mathrm{CH}=\mathrm{CH}_{2}, \delta 5.11\right.$ and 5.60 of 2 ) and appearance of aliphatic protons attribute to the main chain. The proportions of the unit from 2 in the copolymers $(2: \mathrm{St}=1: 9)$ were smaller than that of 2 in feed $(2: S t=1: 5)$. The number-average molecular weight $(\mathrm{Mn})$ and molecular weight distribution $(M w)$ of $\mathbf{3}$ were 14,700 and 1.5 respectively determined by GPC. The obtained polymer was soluble in chloroform, diethyl ether, THF, 1,4-dioxane, acetone, DMF, and DMSO, but insoluble in hexane, methanol, and water (Table 1).

3.2. Reaction of copolymer $\mathbf{3}$ with 4-hydroxybenzaldehyde.
Formyl group of benzaldehyde was known to react with primary amine to yield an imine compound. To use a soluble scavenger resin, 3 was reacted with 4-hydroxybenzaldehyde using triphenylphosphine and DEAD in THF as shown in scheme 3 . ${ }^{1} \mathrm{H}-\mathrm{NMR}$ spectrum of the obtained polymer 4 was shown in Figure 2. The ${ }^{1} \mathrm{H}-\mathrm{NMR}$ spectrum shows the appearance of formyl proton at $\delta 9.86$ and of aromatic protons of aryl aldehyde at $\delta 7.81$ respectively. The reaction of 4-hydroxybenzaldehyde with $\mathbf{3}$ was confirmed.

\subsection{Application as a scavenger reagent of 4 .}

To demonstrate of $\mathbf{4}$ as a scavenger resin for primary amine, benzylamine (1.4 eq for formyl group of 4) was added to a THF solution of 4 at $\mathrm{rt}$ for $24 \mathrm{~h}$ (Scheme 4). ${ }^{1} \mathrm{H}-\mathrm{NMR}$ spectrum of obtained polymer 5 was shown in Figure 3. Imine proton at $\delta 8.31$ and benzyl proton at $\delta$ 4.95 was apparently observed. Whereas the conversion 
Scheme 5. Reaction of 3 with diketene.

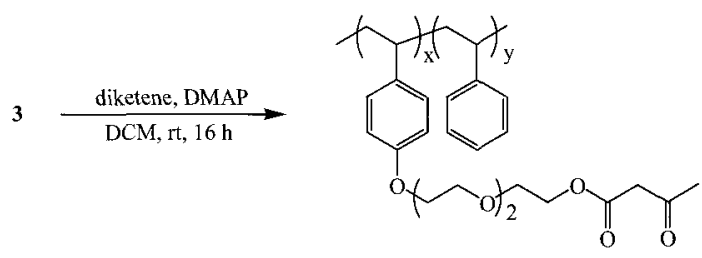

6

Scheme 6. Scavenger model reaction of 6 with benzylamine.

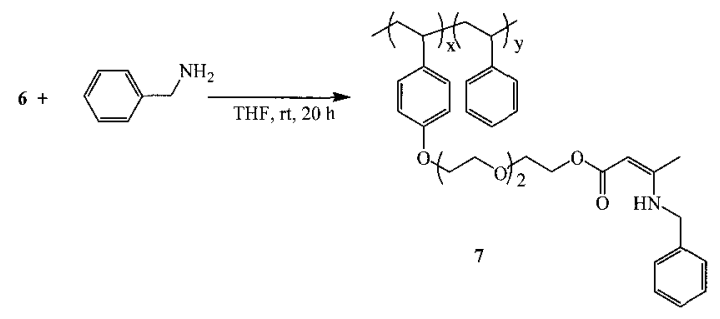

from aldehyde to imine was $67 \%$.

3.4. Reaction of copolymer 3 with diketene.

The reactivity of 4 with benzylamine was not satisfied as a scavenger. The polymer 3 was reacted with diketene using DMAP in dichloromethane at $-78^{\circ} \mathrm{C}$ for $16 \mathrm{~h}$ to introduce $\beta$-ketoester groups. 'H-NMR spectrum of the obtained polymer $\mathbf{6}$ was shown in Figure 4. The ${ }^{1} \mathrm{H}-\mathrm{NMR}$ spectrum shows the appearance of the protons of $\alpha$-methylene at $\delta 3.47$ and of terminal methyl at $\delta 2.24$ respectively. The immobilization of $\beta$-ketoester on 3 was confirmed.

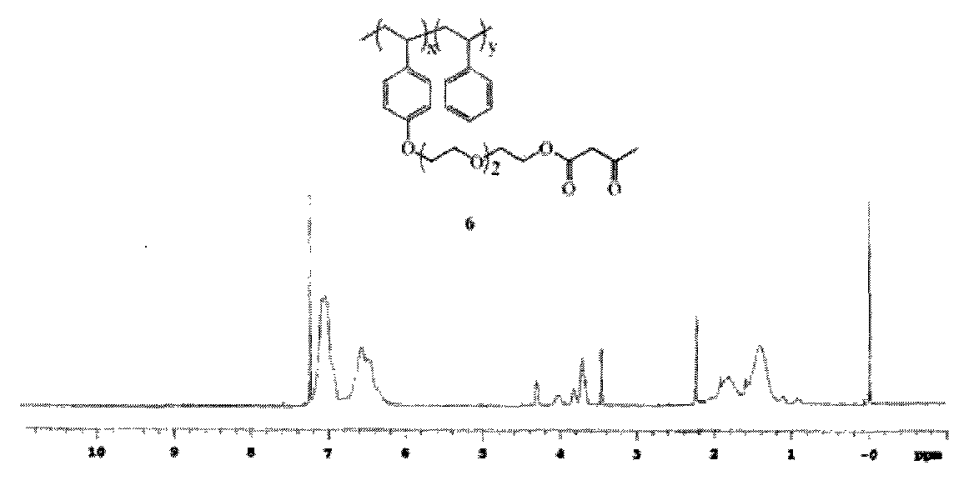

Fig 4 H-NMR of 6

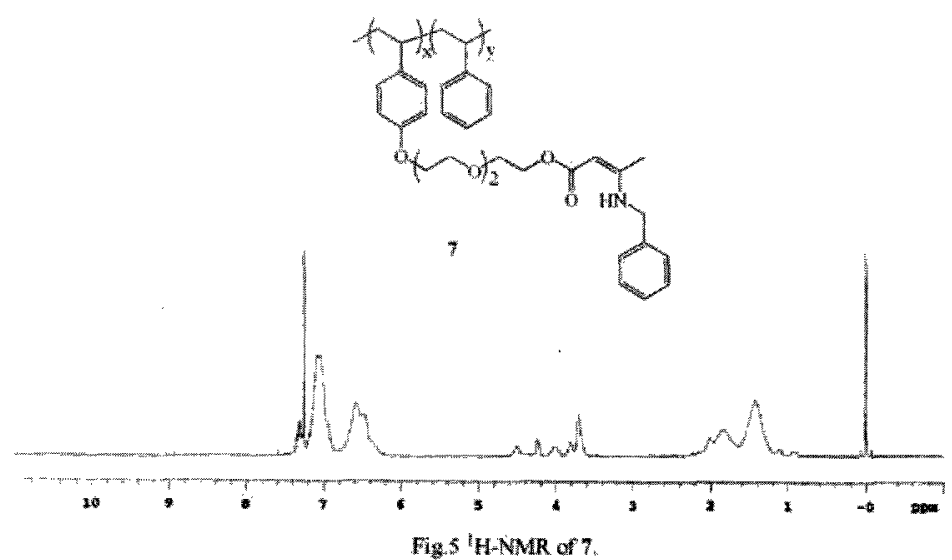

\subsection{Application as a scavenger reagent of 6 .}

To demonstrate of $\mathbf{6}$ as a scavenger resin for similar condition of 3.3., benzylamine was added to a THF solution of 6 at $\mathrm{rt}$ for $20 \mathrm{~h}$ (Scheme 6). ${ }^{1} \mathrm{H}-\mathrm{NMR}$ spectrum of obtained polymer 7 was shown in Figure 5. Aromatic protons of benzylamino groups at $\delta$ 7.37-7.29 and benzyl protons at $\delta 4.24$ was apparently observed, and the reaction proceeded quantitatively. These results show the good performance as a primary-amine scavenger.

\section{Summary}

Polystyrene having triethylene glycol moieties was prepared from copolymerization of 2-\{2-[2-(4-vinylphenoxy)ethoxy]ethoxy\}ethanol with St. The terminal hydroxyl group was reacted with 4-hydroxybenzaldehyde to obtain the polystyrene having formyl group. To further functionalization, the terminal hydroxyl group was reacted with diketene to obtain the polystyrene having $\beta$-ketoester. Both polystyrenes as scavengers were reacted with benzylamine. The polystyrene with $\beta$-ketoester shows good performance as a soluble scavenger resin.

\section{ACKNOWLEDGEMENT}

We are grateful to the NMRC of OIT for financial and instrumental supports.

\section{References}

[1] C. Gil, K. Knepper, S. Bräse, "Polymeric Materials in Organic Synthesis and Catalysis" Edited by M. R. Buchmeiser, WILEY-VCH GmbH \& CO. KGaA (2003) pp. 139-164.

[2] R. Warwass, "Combinatorial Chemistry" Edited by G. Jung, WILEY-VCH Verlag GmbH (1999) pp. 167-228.

[3] B. A. Bunin, "The Combinatorial Index" Accademic Press, San Diego (1998) pp. 11-76.

[4]Z. Yu; S. Alesso; D. Pears; P. A. Worthington; R. W. A. Luke; M. Bradley, Tetrahedrron Lett, 41, 8963-8967 (2000).

[5] O. Shimomura, B. Clapham, C. Spanka, S. Mahajan, K. Janda, J. Comb. Chem. 4, 436-441 (2002).

[6] S. Ley, I. Baxendale, R. Bream, P. Jackson, A. Leach, D. Longbottom, M. Nesi, J. Scott, R. Storer, S. Taylor, Perkin 1, 23 3815-4195 (2000).

[7] M. Guino, E. Brule, Y.Miguel, J. Comb. Chem. 5, 161-165 (2003).

[8] S. Kaldor, M. Siegel, J. Fritz, B. Dressman, P. Hahn, Tetrahedron Lett., 37, 7193-7196 (1996).

[9]Nova Biochem, The Combinatorial Chemistry Catalog, (1999) S64.

(Recieved December 21, 2007 ; Accepted March 6, 2008) 